gross infiltration, those with nodular lesions, and among those with high bacillary density on skin smears.

The very detailed monthly assessment of haematological, hepatic, renal, neurological, visual, and cardiac functions failed to show any toxic effects from clofazimine during the period of observation, and thus confirmed the previously gained impression that in the acutely ill, debilitated leprosy patient clofazimine can be safely administered with gratifying therapeutic results. However, the red-brown pigmentation of the skin that was seen in all the patients, coupled with reddish brown urine and sweat and a tendency to development of dry scaly skin, was disturbing to the younger and fairer patients.

The study does not show the superiority of clofazimine over dapsone, in the dose used in this trial, in terms of bacterial death and clearance, resolution of skin lesions, and the incidence of erythema nodosum leprosum. While further controlled studies for a longer period are necessary, we suggest that dapsone, which is much cheaper and does not cause significant pigmentation, is preferable to clofazimine in the routine management of untreated lepromatous leprosy. Clofazimine could be reserved for patients who are either sensitive or resistant to dapsone as well as for those who are distressed by recurrent chronic erythema nodosom leprosum or recurrent chronic peripheral neuritis or both.

\section{References}

Brechet, R. (1963). International fournal of Leprosy, 31, 549.

Browne, S. G. (1965). Leprosy Review, 36, 13.

Browne, S. G., and Hogerzeil, L. M. (1962). Leprosy Review, 33, 6.

Chang, Y. T. (1962). In Antimicrobiol Agents and Chemotherapy, ed. J. C. Sylvesta, p. 294. Chicago, American Society for Microbiology.

Davey, T. F. (1964). In Leprosy in Theory and Practice, ed. R. G. Cochrane and T. F. Davey, 2nd edn. pp. 115, 400 . Bristol, Wright.

Faget, G. H., et al. (1943). Public Health Reports, 58, 1729.

Karat, A. B. A., Jeevaratnam Anbu, Karat, S., and Rao, P. S. S. (1970) British Medical fournal, $1,198$.

Pettit, J. H. S., Rees, R. J. W., and Ridley, D. S. (1967). International Fournal of Leprosy, 35, 25.

Ridley, D. S. (1964). In Leprosy in Theory and Practice, ed. R. G. Cochrane and T. F. Davey, 2nd edn., p. 620. Bristol, Wright.

Shepard, C. C., and McRae, D. H. (1965). Fournal of Bacteriology, 89, 365. Williams, T. W., et al. (1965). International fournal of Leprosy, 33, 767.

\title{
Coagulation Defects in Hypoxic Full-term Newborn Infants
}

\author{
M. A. CHADD, P. C. ELWOOD, O. P. GRAY, S. M. MUXWORTHY
}

British Medical fournal, 1971, 4, 516-518

\section{Summary}

Blood clotting was examined in 24 consecutive full-term newborn infants with hypoxia and 23 normal control infants. There was evidence of a gross alteration in the clotting process in the hypoxic infants. The degree of disturbance in clotting seemed to be dependent on the severity of the hypoxia, suggesting a causal relationship. The mechanism involved seemed to be intravascular coagulation. The consumption of clotting factors involved led to the appearance of a haemorrhagic diathesis. This effect seemed to be of short duration, suggesting that direct liver damage plays at most a minor part.

Though there was no evidence of damage in the infants who survived, it is possible that intravascular coagulation induced by hypoxia, by leading to deposition of fibrin, may cause damage to vital organs. Further studies will be required to examine this possibility.

\section{Introduction}

Intracranial haemorrhage is a common finding in neonatal deaths of full-term infants. In a small selected series Haller et al. (1956) found an incidence of $9.5 \%$, Gröntoft (1953) an incidence of over $30 \%$, but the British perinatal birth survey (Butler and Bonham, 1963) showed an incidence of $7.6 \%$ for intraventricular haemorrhage and cerebral birth trauma.

\footnotetext{
Department of Child Health, Welsh National School of Medicine, Cardiff Royal Infirmary, Cardiff CF2 1SZ

M. A. CHADD, M.B., B.CH., D.C.H., Research Fellow

O. P. GRAY, F.R.C.P., D.C.H., Professor

S. M. MUXWORTHY, A.I.M.L.T., Research Technician

Epidemiology Unit of the Medical Research Council, Cardiff CF2 3AS P. C. ELWOOD, M.D., D.C.H., Scientific Member
}

Serious intracranial haemorrhage may be due not only to physical trauma but to other adverse factors, such as a poor coagulation state. Wefring (1962) suggested one cause of haemorrhage to be prothrombin complex deficiency, and investigation of preterm infants has confirmed this and shown an association between intracranial haemorrhage and a deficiency of factor II complex (Gray et al., 1968), but the frequency of haemorrhage from this cause is largely unknown. The level of factor II, which is normally low at birth, may be further depressed by hypoxia, but most of the work which has suggested this has been done in preterm infants and there is a lack of information on the role of this mechanism in fullterm infants. That non-traumatic haemorrhage may be, in part, due to coagulation deficiencies other than factor II has been established in the preterm infants (Hathaway et al., 1969) but there are only a few isolated case reports relating to full-term infants (Chessells and Wigglesworth, 1970).

The exact nature of the process by which hypoxia causes haemorrhage is incompletely understood. It has generally been assumed that the process is basically one of direct liver damage, but recent studies (Aballi and de Lamerens, 1962; Hathaway et al., 1969; Berglund, 1970) have indicated that a consumption coagulopathy, usually following disseminated intravascular coagulation, may be a most important mechanism. In view of these areas of doubt we have set out to determine the role of hypoxia in full-term infants as a cause of coagulation disorders. The present study has been undertaken with a comprehensive series of tests over an extended period of time, and the results have been correlated with biochemical and clinical assessments of hypoxia.

\section{Cases and Methods}

Forty-seven full-term infants were studied. These were 24 consecutive hypoxic full-term babies admitted to our unit and 23 full-term control babies who showed no evidence of hypoxia during delivery. These latter were chosen from the nursery, and parental consent for their inclusion was obtained. The Apgar score was estimated by the paediatrician attending 
the birth. The control babies had a one-minute Apgar score of 5 or more, and at 6 hours of age their base deficit was 5 or less. Hypoxia was diagnosed by an Apgar score of 5 or less at one minute after birth, or by failure to establish regular respirations by the age of 3 minutes. Biochemical confirmation of hypoxia was obtained from blood gas studies on capillary blood obtained from a warm heel and the base deficit was used as a further estimate of the degree of hypoxia.

Blood for clotting tests was taken from a femoral venepuncture and placed into $3.8 \%$ trisodium citrate in a plastic tube ( 9 vol. blood to 1 vol. citrate) and centrifuged immediately at 3,000 r.p.m. for 10 minutes at $5^{\circ} \mathrm{C}$. Blood for estimation of fibrin degradation products was taken into plastic tubes containing aprotinin (Trasylol), a fibrinolytic inhibitor. The tests used were the kaolin cephalin clotting time (K.C.C.T.); the thrombin clotting time (T.C.T.), which measures the third stage of coagulation; and the thrombotest (uncorrected for haemoglobin level), which measures the prothrombin complex, factors II, VII, IX, and X. Other aids to detection of a consumption coagulopathy were the platelet count, estimated with a phase contrast microscope, and the fibrin degradation products (F.D.P.) level, estimated with the Burroughs Wellcome test which is based on the haemagglutination methods of Murakami et al. (1965) and Merskey et al. (1966.) The clotting tests were performed by one of us (S.M.M.) who was unaware of the clinical state of the child. All the clotting tests were done in the first instance within 12 hours of birth and repeated at 24-hour intervals for a total of three days.

Each set of coagulation test results for the kaolin cephalin clotting time and thrombin clotting time were compared with the result obtained from a healthy adult volunteer and then expressed as a ratio-that is, the time taken for the babies' blood to clot divided by the time taken for the adult control blood to clot.

\section{Results}

Table I shows the two groups of infants, the hypoxic and the controls, who were similar with regard to sex, maturity, and birth weight. On the other hand, in the hypoxic group antenatal complications were more common. At birth their base deficit was more pronounced, and during the first 24 hours of life a rectal temperature below $35^{\circ} \mathrm{C}$ was detected in a greater proportion. Two of the hypoxic babies but none of the control babies died during the first six days.

Table II summarizes the results of the clotting tests. All the mean levels are very different in the two groups. The directions of the differences are all consistent with an impair-

TABLE I-The Two Groups of Infants (Means \pm Standard Deviations)

\begin{tabular}{|c|c|c|c|c|}
\hline & & Hypoxic & Controls & Difference \\
\hline 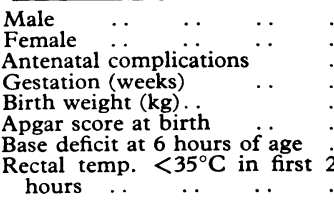 & $\begin{array}{l}\cdots \\
\cdots \\
\cdots \\
\cdots \\
2 \dot{2} \\
\cdots\end{array}$ & $\begin{array}{c}9 \\
15 \\
46 \pm 10 \cdot 2 \% \\
35 \cdot 1 \pm 0 \cdot 38 \\
3 \cdot 2 \pm 0 \cdot 13 \\
2 \cdot 5 \pm 0 \cdot 33 \\
7 \cdot 3 \pm 1 \cdot 01 \\
4 \pm 4 \cdot 1 \%\end{array}$ & $\begin{array}{c}10 \\
13 \\
17 \pm 7 \cdot 8 \% \\
35 \cdot 5 \pm 0 \cdot 13 \\
3 \cdot 4 \pm 0 \cdot 12 \\
7 \cdot 4 \pm 0 \cdot 22 \\
4 \cdot 6 \pm 0 \cdot 16 \\
25 \pm 8 \cdot 8 \%\end{array}$ & $\begin{array}{l}\quad P>0.05 \\
P<0.05 \\
P>0.05 \\
P>0.05 \\
P<0.001 \\
P<0.01\end{array}$ \\
\hline
\end{tabular}

TABLE II-Means etc. of Tests Relevant to Clotting in the Two Groups. (Numbers of Infants for Whom Data are Available are Shown in Parentheses)

\begin{tabular}{|c|c|c|c|c|c|}
\hline & & Hypoxic & Controls & $\begin{array}{l}\text { Homogeneity } \\
\text { of Variances }\end{array}$ & $\begin{array}{l}\text { Homogeneity } \\
\text { of Means* }\end{array}$ \\
\hline $\begin{array}{l}\text { K.C.C.T. (ratio) } \\
\text { T.C.T. (ratio) } \\
\text { Thrombotest }(\%) \\
\text { F.D.P. ( } \% \text { ) } / \mathrm{ml}) \\
\text { Platelets }\left(10^{3} / \mathrm{mm}^{3}\right)\end{array}$ & $\begin{array}{l}\cdots \\
\cdots \\
\cdots \\
\cdots\end{array}$ & $\begin{array}{r}1 \cdot 6(23) \\
2 \cdot 2(23) \\
19 \cdot 9(24) \\
28 \cdot 8(10) \\
133.5(23)\end{array}$ & $\begin{array}{r}1.3(23) \\
1.3(23) \\
27.8(23) \\
10 \cdot 6(12) \\
161.9(23)\end{array}$ & $\begin{array}{l}\mathrm{P}<0.001 \\
\mathrm{P}<0.001 \\
\mathrm{P}>0.05 \\
\mathrm{P}<0.001 \\
\mathrm{P}<0.001\end{array}$ & $\begin{array}{l}P<0.001 \\
P<0.05 \\
P>0.05 \\
P<0.001 \\
P<0.05\end{array}$ \\
\hline
\end{tabular}

* Original data (except those for the thrombotest) transformed to log base 10 for he tests of homogeneity of means. ment of clotting, and an increase in fibrinogen consumption in the hypoxic babies. The variances of the distributions within the groups for each test, except the thrombotest, differ significantly (for all $\mathrm{P}<0.001$ ). This difference in variances implies the two groups differ greatly, and in every case (again except for the thrombotest) the variance in the hypoxic group is larger than in the control group. Because of these differences in variances, comparisons of means is difficult. They were compared, however, after transformation of the original data (except the thrombotest) to logarithms, and this confirmed that all the means (except the thrombotest) differ significantly at $\mathrm{P}<0.05$. These statistics are, therefore, indicative of a grossly altered clotting state in the hypoxic babies.

The data for the tests performed after the first 12 hours of life were examined, and these showed no evidence of any important or statistically significant difference between the two groups of infants.

The correlation between the Apgar score and each of the tests was examined (Table III). There is a significant (at $P<0.05$ ) association for K.C.C.T., T.C.T., and F.D.P., and the closest association is probably with F.D.P. These data suggest that the degree of change in clotting and fibrinogen consumption are dependent on the severity of hypoxia at birth.

TABLE III-Correlation Coefficients ( $r$ ) and Standard Errors between Apgar Score and Each of the Tests Relevant to Clotting (Numbers of Pairs from which the Coefficients are Derived are Shown in Parentheses)

\begin{tabular}{|c|c|c|c|c|}
\hline & & Controls & Hypoxic & All Infants \\
\hline $\begin{array}{l}\text { K.C.C.T. } \\
\text { T.C.T. .. } \\
\text { Thrombotest } \\
\text { F.D.P. .. } \\
\text { Platelets } \\
\quad\left(10^{3} / \mathrm{mm}^{3}\right)\end{array}$ & $\begin{array}{l}\cdots \\
\cdots \\
\cdots\end{array}$ & 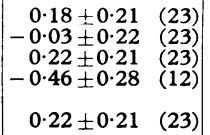 & $\begin{array}{r}-0.61 \pm 0.17^{*}(23) \\
-0.52 \pm 0.19^{*}(23) \\
-0.03 \pm 0.21 \quad(24) \\
-0.58 \pm 0.29 \quad(10) \\
0.12 \pm 0.22 \quad(23)\end{array}$ & $\begin{array}{r}-0.29 \pm 0.14^{*}(46) \\
-0.52 \pm 0.13^{*}(46) \\
0.33 \pm 0.14^{*}(47) \\
-0.59 \pm 0.59^{*}(22) \\
0.40 \pm 0.40^{*}(46)\end{array}$ \\
\hline
\end{tabular}

* Tests are significant. $P<0.05$.

\section{Discussion}

The results presented here establish that babies who are hypoxic during birth, compared with normal control babies, have an impaired clotting state. That the relationship is causal is suggested by the fact that the more severe the hypoxia the more abnormal are the clotting tests (Table III). The process involved seems to be one of consumption coagulopathy. This is indicated by the raised levels of F.D.P., the lowered platelet counts, and the prolongation of the T.C.T. This last test becomes abnormal when fibrinogen levels are lowered or when there is a raised level of F.D.P., these latter acting as anticoagulants, interfering with polymerization of the fibrin clot (Bang, 1961). The infants who survived seem to have recovered from these effects of hypoxia by the second day of life. As the F.D.P. seem to be quickly eliminated, direct liver damage, at least in term infants, is therefore likely to play only a minor part in the process.

Inspection of the original data shows that the K.C.C.T. was reduced in some of the infants shortly after birth; almost all of these were hypoxic. A low K.C.C.T. suggests a hypercoagulable state, and during active clotting, which was probably taking place in some of these hypoxic infants, certain factors are consumed and later there is a prolongation of the K.C.C.T. A similar hypercoagulable stage has been detected in animals before the development of the hypocoagulable state (Crowell et al., 1955).

This work suggests that disseminated intravascular coagulation is a frequent factor of major importance in infants who die shortly after birth with haemorrhage. The fact that the thrombotest indicated no important difference between the two groups suggests that hypoprothrombinaemia alone is not an important factor in infants, and as the coagulation defect seems to be mainly due to deficiencies other than factor II it is unlikely that it would respond to vitamin $\mathrm{K}$ therapy. 
The high correlation between the degree of hypoxia and both T.C.T. and F.D.P. levels indicates that these are useful tests in the evaluation of the clotting status of a newborn infant. The two tests are interdependent, but whereas it is possible to do the T.C.T. in minutes, estimation of F.D.P. takes several hours.

Despite the pronounced impairment of the clotting state of these infants, there was no overt evidence of haemorrhage. Nevertheless, it cannot be assumed that such infants escape unscathed from the hypoxic episode, since the very process which caused the consumption of coagulation factors results in deposition of fibrin, and this may have led to damage of vital organs such as the brain. That damage can result is suggested by a recent report (Bryant et al., 1970) and further work is being conducted in this centre to evaluate this possible effect.

We acknowledge the co-operation willingly given at all times by Sister E. Owen and the nursing staff of the special care unit. The work was carried out while one of us (M.A.C.) had tenure of a research scholarship from the Wellcome Trust, and another (S.M.M.) was in receipt of a grant from the Clinical Research
Board of the University Hospital of Wales (Cardiff) Hospital Management Committee.

\section{References}

Aballi, A. J., and de Lamerens, S. (1962). Pediatric Clinics of North America, 9, 785 .

Bang, N. U. (1961). Thrombosis et Diathesis Haemorrhagica, 6, Suppl. No. 1, p. 262

Berglund, G. (1970). Acta paediatrica Scandinavica, 59, 664

Bryant, G. M., Gray, O. P., Fraser, A. J., and Ackerman, A. (1970). British Medical fournal, 4, 707.

Butler, N. R., and Bonham, D. G., (1963). Perinatal Mortality. London, Livingstone.

Chessells, J. M., and Wigglesworth, J. S. (1970). Archives of Disease in Childhood, 45, 539.

Crowell, J. W., Sharpe, G. P., Lambright, R. L., and Read, W. L., (1955). Surgery, 38, 696 .

Gray, O. P., Ackerman, A., and Fraser, A. J. (1968). Lancet, 1, 545

Gröntoft, O. (1953). Acta obstetricia et gynecologica Scandinavica, 32, 308. Haller, E. S., Nesbitt, R. E. L., and Anderson, G. W. (1956). Obstetrical and Gynecological Survey, 2, 179.

Hathaway, W. E., Mull, M. M., and Pechet, G. S. (1969). Pediatrics, 43, 233.

Merskey, C., Kleiner, G. J., and Johnson, A. J. (1966). Blood, 28, 1.

Murakami, M., et al. (1965). Fapanese fournal of Clinical Pathology, 13, 542.

Wefring, K. W., (1962). Fournal of Pediatrics, 61, 686.

\title{
Comparative Nephrotoxicity of Aspirin and Phenacetin Derivatives
}

\author{
I. C. CALDER \\ C. C. FUNDER, \\ C. R. GREEN, \\ K. N. HAM, J. D. TANGE
}

British Medical fournal, 1971, 4, 518-521

\section{Summary}

Both aspirin and phenacetin derivatives were shown to be nephrotoxic when administered to rats as a single intravenous injection. Phenacetin derivatives tended to produce more severe renal damage and to be nephrotoxic in smaller doses than aspirin derivatives. With the exception of a single derivative, the renal lesions were confined to the proximal convoluted tubule, even after administration of compounds which under other conditions have induced renal papillary necrosis.

\section{Introduction}

Though an association between abuse of analgesics and renal damage has been recorded many times by groups of observers from different countries, the processes causing the renal lesions are not known, and there is not even agreement regarding the identity of the analgesic compound responsible for the damage (Koutsaimanis and de Wardener, 1970; Nanra and Kincaid-Smith, 1970). Since the acute effects of these compounds on the mammalian nephron can be conveniently assessed after intravenous administration in rats (Green, Ham, and Tange, 1969), this experimental method has been used to compare the nephrotoxicity of aspirin and phenacetin derivatives.

University of Melbourne, Melbourne, Australia

I. C. CALDER, PH.D., Lecturer in Organic Chemistry

C. C. FUNDER, M.B., B.S., N.H. and M.R.C. Research Scholar

C. R. GREEN, PH.D., Reader in Pathology

K. N. HAM, M.D., PH.D., Lecturer in Pathology

J. D. TANGE, M.R.C.P., F.R.A.C.P., Senior Lecturer in Pathology

\section{Methods}

Female hooded rats, weighing about $200 \mathrm{~g}$, were divided into groups of five animals and individually marked. They were given tap-water to drink and a pellet diet.

Compounds under investigation were injected as the hydrochloride or as the sodium salt (Tables I and II). Single intravenous injections of $1 \mathrm{ml}$ or less were given, and the dose and concentration were determined in preliminary experiments, which also allowed assessment of the maximum dose compatible with survival. Animals were lightly anaesthetized with ether for tail vein injection and were killed by bleeding under ether anaesthesia 48 hours later. The kidneys were removed, fixed in $10 \%$ neutral formalin, and processed by routine methods for light microscopy.

Twenty-two compounds were tested, all on groups of five animals. Some compounds were tested at several dose levels (Tables I and II). Compounds were either commercially available or were synthesized by standard techniques and all samples purified before use.

Total $p$-aminophenol was estimated after hot acid hydrolysis and $\mathrm{O}$-conjugated $p$-aminophenol was estimated after hydrolysis with glusulase. $p$-Aminophenol was determined by the indophenol colorimetric method (Tompsett, 1969). Two groups, each of five rats, were used as controls, and these animals were given a single intravenous injection of $1 \mathrm{ml}$ of sterile normal saline.

\section{Results}

The nephrotoxic effect of these aspirin and phenacetin derivatives was manifest as necrosis of the proximal convoluted tubule. With the exception of the coincident renal papillary necrosis produced by $m$-aminosalicylic acid, this was the only lesion found in the experiment. Four grades of proximal 